\section{BMJ Paediatrics Open}

\title{
Parenting a child with congenital cytomegalovirus infection: a qualitative study
}

Tushna Vandrevala (1) , ${ }^{1}$ Victoria Barber, ${ }^{2}$ Evas Mbire-Chigumba, ${ }^{2}$ Anna Calvert, ${ }^{3}$ Caroline Star, ${ }^{4}$ Asma Khalil, ${ }^{5}$ Paul Griffiths, ${ }^{6}$ Alexander S Book, ${ }^{7}$ Gayle M Book, ${ }^{7}$ Paul Heath, ${ }^{8}$ Christine E Jones ${ }^{9}$

To cite: Vandrevala T, Barber V, Mbire-Chigumba E, et al. Parenting a child with congenital cytomegalovirus infection: a qualitative study. BMJ Paediatrics Open 2020;4:e000844. doi:10.1136/ bmjpo-2020-000844

Received 19 August 2020 Revised 8 October 2020 Accepted 19 0ctober 2020

Check for updates

(C) Author(s) (or their employer(s)) 2020. Re-use permitted under CC BY-NC. No commercial re-use. See rights and permissions. Published by BMJ.

${ }^{1}$ Psychology, Kingston University, Kingston-Upon-Thames, UK

${ }^{2}$ Psychology, Kingston University, Kingston-Upon-Thames, UK ${ }^{3}$ Institute of Infection and Immunity, St George's, Unite, London, UK

${ }^{4}$ CMV Action, London, UK ${ }^{5}$ Fetal Medicine Unit, St George's University Hospital, London, UK

${ }^{6}$ Virology, UCL, London, UK ${ }^{7}$ Parent of child with congenital CMV infection, London, UK ${ }^{8}$ University of London Saint George's, London, UK

${ }^{9}$ Faculty of Medicine and Institute for Life Sciences, University of Southampton, Southampton, UK

Correspondence to Dr Tushna Vandrevala; t. vandrevala@kingston.ac.uk

\section{ABSTRACT \\ Background Congenital cytomegalovirus (CMV)} is the most common infectious cause of congenital disability, which can cause lifelong impairments including sensorineural hearing loss and developmental delay. This study aimed to explore the experiences of parenting a child with congenital CMV and the impact this has on families. Methods Ten parents living with a child with congenital CMV in the UK participated in semistructured interviews and data were analysed using thematic analysis.

Results The findings illustrate that delays in making the diagnosis of congenital CMV are associated with parental distress and lack of knowledge about CMV among medical professionals can exacerbate this distress. Parents expressed frustration about not knowing about CMV infection during their pregnancies and therefore not having the opportunity to take measures to reduce their risk of acquiring CMV while pregnant. The uncertainty about the long-term outcomes of children with congenital CMV adds additional emotional burden for parents. Family and wider societal networks have the potential to facilitate coping and alleviate stress, but the lack of awareness of CMV acts as a barrier to receiving support from family and friends. Conclusions There is a need to increase awareness of CMV among medical professionals, pregnant women and wider society to improve the diagnostic process and to provide better support for families caring for children with congenital CMV infection.

\section{INTRODUCTION}

Congenital cytomegalovirus (CMV) is the most common non-genetic cause of preventable childhood sensorineural hearing loss (SNHL) and neurodevelopmental delay. ${ }^{1}$ CMV is transmitted through saliva, urine and other bodily fluids of young children. Pregnant women may lower their risk of transmitting CMV by following risk-reducing measures, such as hand washing and avoiding contact with saliva and urine. Currently in the UK, there is no antenatal or postnatal screening and no licensed vaccine or routine treatment of CMV infection in pregnancy. Maternal CMV infection is often asymptomatic or associated with a mild influenza-like
What is known about the subject?

Congenital cytomegalovirus (CMV) is the most common non-genetic cause of childhood neurodevelopmental delay and sensorineural hearing loss (https:// www.nhs.uk/conditions/cytomegalovirus-cmv/).

- The nature of the condition has an impact on the experience of parenting a child with special needs.

- In-depth information about parenting a child with congenital CMV will help develop interventions that are not a case of 'one size fits all'.

\section{What this study adds?}

Delays in the diagnostic process and failures in post-diagnostic support were perceived by parents to be exacerbated by the lack of awareness of CMV among medical professionals.

- Parents expressed frustration of not knowing about CMV during their pregnancies and of ways to prevent acquisition of infection, and the uncertainty and unpredictability of congenital CMV added additional emotional strain on parents.

Family and wider societal networks have the potential to facilitate coping and alleviate stress, but the lack of awareness of CMV in society acted as a barrier.

illness, making clinical diagnosis challenging in pregnancy.

It is estimated that $0.2 \%-0.5 \%$ of newborns are affected by congenital CMV (cCMV) in Europe $^{2}$ and $0.3 \%-0.4 \%$ in the UK. ${ }^{3}$ The majority of infants with cCMV are asymptomatic, with no clinically obvious signs at birth. However, around $10 \%-15 \%$ of congenitally infected infants have significant neurodisability, ${ }^{4}$ SNHL, ${ }^{5}$ cerebral palsy and visual impairments. ${ }^{6}$ This broad clinical spectrum extends through childhood with many only developing symptoms later in life. The ability to predict at the point of diagnosis whether and to what extent, a child will be affected is 
imperfect, leaving parents with a degree of uncertainty about the long-term outcomes of their child. Despite the birth prevalence of cCMV being higher than other congenital conditions (spina bifida, Trisomy 21 or congenital toxoplasmosis infection ${ }^{1}$ ), CMV is less well known among women of childbearing age. ${ }^{78}$

Living with a child with additional needs can undoubtedly have profound effects on the family. ${ }^{9}$ One in 20 children have a disability and $99 \%$ are supported by their families at home. ${ }^{10}$ Studies have investigated the impact of living with a child with autism, ${ }^{11-13}$ spina bifida ${ }^{14}$ and Trisomy $21^{15} 16$ and consistently highlight that family carers of children with additional needs face considerable stress and despair at the time of diagnosis. ${ }^{17} 18 \mathrm{Argu}-$ ably, impacts on families depend on the type and severity of the condition, physical, emotional and financial status of the family. ${ }^{9}$ Parenting children with 'invisible' disabilities, language delay, behavioural and social problems are particularly stressful for families. ${ }^{12}$ Perceptions of disability rather than characteristics of the child or severity of the disability contributes to burdens on family carers. ${ }^{19}{ }^{20}$ However, some parents report an improvement in family cohesion and functioning. ${ }^{21-23}$

There are no published studies on the lived experiences of parenting a child with cCMV. While the wider literature gives us an indication of the experiences of families of children with additional needs, these are likely to be different for families living with children with cCMV, due to the mode of transmission and pregnant women's ability to potentially lower their risk of acquiring CMV by following risk-reducing measures ${ }^{24}$; a strategy which many pregnant women are motivated to engage with. ${ }^{25}$ The experiences of parenting a child with cCMV may be distinctly different to parenting a child with other disabilities, therefore the aim of the current study was to examine the lived experiences of cCMV and impact on parents.

\section{METHOD}

Design

To obtain rich descriptions of participants' experiences, ${ }^{26}$ a qualitative research approach was used.

\section{Patient and public involvement}

Our project steering group which included pregnant women, parents living with children with cCMV (coauthors ASB and GMB and representatives from charities supporting families affected by cCMV (CS) ) played a role in designing and disseminating the findings of this study.

\section{Recruitment and participants}

On receiving approval from Health Research Authority South Central-Oxford C Research Ethics Committee (16/ $\mathrm{SC} / 0683)$, parents of children affected by cCMV infection were invited to take part in the study. CMV Action (https://cmvaction.org.uk), a UK-based organisation for parents and volunteers who raise awareness of CMV and campaign for better prevention measures, invited parents to participate in the study via their website. Opportunity sampling was used to recruit 10 parents (one man and nine women). Eligible participants needed to satisfy the following criteria: (a) be at least 18 years of age; (b) have a child or young person diagnosed with cCMV; (c) ability to comprehend and speak English to a sufficient level; (d) willing to participate and available to be interviewed. Of the 24 individuals who approached the researchers to register their interest in participating in this study, 14 families did not respond further, or a convenient time for interview could not be arranged. Participant characteristics are presented in table 1 . This study did not intend to generate theoretical models, therefore theoretical saturation (or data saturation) was not considered.

\section{Data generation}

Data were generated through semistructured interviews (see box 1) developed by authors TV, VB and CEJ, and interviews were conducted by VB. Interviews were piloted and revised in accordance with the iterative process of qualitative research, where concurrent data collection and analysis take place. This format was chosen to ensure that core questions were asked while providing scope for participants to explore relevant, but unanticipated domains of experience and reflection that were important to them. Topics included experience of CMV from pre-diagnosis through to caring for a child with cCMV in their daily family lives. Five interviews were conducted face-to-face in the participants' homes and the remainder via video conferencing to enable data collection from different parts of the country. Interviews lasting 60-90 min were digitally recorded and transcribed. Field notes were made after the interviews.

\section{Analytical strategy}

Transcripts were analysed using thematic analysis to identify a set of meaningful patterns or themes and subthemes associated with the research questions. ${ }^{27}$ This process of analysing qualitative data has been identified as a useful method for identifying, analysing and reporting patterns within data through the development and detailed description of themes. The analysis was undertaken by TV, VB and EM-C and was guided by Braun and Clarke's ${ }^{2727}$ six stages of familiarisation with the data, identification of initial codes, searching for themes, reviewing themes and subthemes, defining and naming themes and subthemes, and writing up the analysis. NVivo V.11 computer software was used to manage the data. TV, VB and EM-C familiarised themselves with the data. EM-C was responsible for coding and searching for themes. After this point, discussions between TV, VB and EM-C informed the latter stages of the process, with TV taking primary responsibility for writing the results. High-quality analysis was promoted through close alignment with recognised criteria for good qualitative research, such as grounding interpretations in examples from the data (which allows readers to confirm or query interpretations), conducting credibility checks and optimising coherence across the study. ${ }^{28} 29$ 
Table 1 Participant characteristics

\begin{tabular}{|c|c|}
\hline & $\mathbf{N}(\%)$ \\
\hline \multicolumn{2}{|l|}{ Gender } \\
\hline Female & $9(90)$ \\
\hline Male & $1(10)$ \\
\hline \multicolumn{2}{|l|}{ Age (years) } \\
\hline $18-24$ & $0(0)$ \\
\hline $25-40$ & $6(60)$ \\
\hline $41-50 y$ & $4(40)$ \\
\hline \multicolumn{2}{|l|}{ Marital status } \\
\hline Single (never married) & $3(30)$ \\
\hline Married/civil partner & $7(70)$ \\
\hline \multicolumn{2}{|c|}{ Age of child when diagnosed with congenital CMV } \\
\hline From birth & $3(30)$ \\
\hline Under 12 months & $4(40)$ \\
\hline 13 months -2 years & $1(10)$ \\
\hline $3-4$ years & $1(10)$ \\
\hline 5 years and above & $1(10)$ \\
\hline \multicolumn{2}{|l|}{ Age of child at time of interview } \\
\hline $0-12$ months & $1(10)$ \\
\hline $13-23$ months & $0(0)$ \\
\hline $2-5$ years & $5(50)$ \\
\hline $6-10$ years & $2(20)$ \\
\hline $11-15$ years & $2(20)$ \\
\hline \multicolumn{2}{|l|}{ Severity of congenital CMV } \\
\hline Hearing loss (unilateral or bilateral) & $6(60)$ \\
\hline Developmental and motor delay & $1(10)$ \\
\hline Severely disabled & $2(20)$ \\
\hline Unknown & $1(10)$ \\
\hline \multicolumn{2}{|l|}{ Ethnicity } \\
\hline White English & $9(90)$ \\
\hline Other British & $1(10)$ \\
\hline \multicolumn{2}{|l|}{ Parental highest qualifications } \\
\hline GCSE/BTEC or equivalent & $1(10)$ \\
\hline AS/A-levels or equivalent & $2(20)$ \\
\hline PGCert/PGDip or equivalent & $1(10)$ \\
\hline BSc/BA or equivalent & $2(20)$ \\
\hline $\begin{array}{l}\text { MSc/Postgraduate diplomas or } \\
\text { equivalent }\end{array}$ & $4(40)$ \\
\hline
\end{tabular}

AS, Advanced Subsidiary; BA, Bachelor of Arts; BSc, Bachelor of Science; BTEC, Business and Technology Education Council; CMV, cytomegalovirus; GCSE, General Certificate of Secondary Education; MSc, Master of Science; PGCert, postgraduate certificate; PGDip, postgraduate diploma.

\section{RESULTS}

Our 10 participants described the essence of the lived experience of parenting a child with cCMV can be illustrated by the following themes: difficulties associated with establishing a diagnosis of cCMV; burden associated

\section{Box 1 Interview guide}

The aim of this study is to explore your experiences with cytomegalovirus (CMV) and the impact CMV may have had on you and your family. We are interested to hear your story. The information provided will be used to create a short film about CMV that will be used to educate recently pregnant women and their families about the preventative strategies they can adopt.

\section{Part 1-CMV questions pre-diagnosis}

- I would like to start with asking you about when you first heard about CMV?

- Did you know anyone who has had CMV?

- How did you think CMV might be caught?

- How much were you told about how CMV could be prevented?

\section{Part 2-diagnosis-related questions}

- How did you find out about your child having CMV?

- How and who told you that your child had CMV?

- What was your initial reaction to hearing the diagnosis?

- What were your biggest anxieties at this time?

\section{Part 3-post-diagnosis questions}

- Whose advice did you value when getting information about CMV?

- Had you been informed about CMV prior to your/your partner's pregnancy/ies?

- In retrospect, do you think realistically that you would adopt any measures to reduce the risk of getting CMV? If so, which one(s)?

- What do you think would motivate you pre-diagnosis to adopt some of these hygiene measures and what would practically help you?

- What barriers do you think would stop you adopting measures to reduce the risk of catching CMV in pregnancy?

What do you wish you had known, pre-diagnosis?

\section{Part 4-experiences of CMV in the family}

- Can you tell me a little about your experiences of caring for a child with CMV?

- Please can you tell me about a typical day living with a family member with CMV?

- What are some of the biggest challenges for you and the rest of the family?

- What impact has this had on you?

\section{Part 5-educational video perceptions/feedback}

- We are developing an educational video on CMV for pregnant women and their partners. From your experience what information should it include?

Where should we show it and to whom?

- What would be the ideal way to access the video? In what language-preventative or reduction language?

Exit question: anything else you would like to share or raise?

with caring for a child with cCMV; and societal networks which have the potential to facilitate coping and alleviate stress (table 2).

\section{Difficulties associated with establishing a diagnosis of congenital CMV}

None of the participants had heard of CMV prior to their child's diagnosis. Participants suggested that medical professionals struggled to arrive at a diagnosis of cCMV and the process was often complicated by errors, poor communication and extended delays. According to 
Table 2 Theme and subthemes

\begin{tabular}{ll}
\hline Themes & Subthemes \\
\hline $\begin{array}{l}\text { Difficulties associated with } \\
\text { establishing a diagnosis of } \\
\text { congenital CMV }\end{array}$ & $\begin{array}{l}\text { Shock of diagnosis } \\
\text { Lack of awareness among } \\
\text { medical community } \\
\text { Disorganised pathways to } \\
\text { diagnosis }\end{array}$ \\
$\begin{array}{l}\text { Burden associated with } \\
\text { caring for a child with } \\
\text { congenital CMV }\end{array}$ & $\begin{array}{l}\text { Dealing with uncertainty and } \\
\text { unpredictability } \\
\text { Loss of a dream } \\
\text { Guilt and responsibility }\end{array}$ \\
$\begin{array}{l}\text { Societal network: } \\
\text { facilitators and barriers to } \\
\text { coping }\end{array}$ & $\begin{array}{l}\text { Support (or lack of support) } \\
\text { from family and community } \\
\text { Support (or lack of support) } \\
\text { from professionals } \\
\text { Raising awareness and } \\
\text { educating wider community }\end{array}$ \\
\hline
\end{tabular}

CMV, cytomegalovirus.

participants' perceptions, difficulty with diagnosis, disorganisation and lack of support post-diagnosis were a result of the lack of knowledge and awareness within the medical community. Participants were shocked and angry about the lack of information provided to them at the time of their pregnancies-and therefore the missed opportunities to reduce the risk of acquiring CMV infection in pregnancy-and the lack of post-diagnostic support, describing the experience as 'traumatic due to the uncertainty, the lack of knowledge and the lack of understanding'.

Participants were despondent about the missed opportunities and misdiagnosis, which left them ill-prepared to spot changes in their child's condition. In some cases, professionals repeatedly assured participants not to worry, but the participants reported having 'this gut feeling' that something might be wrong and living with regret for not acting on it sooner. Participants discussed the lack of coordinated approach to the diagnosis and how the National Health Service (NHS) worked in silos, which hindered the much-needed support they could access for their child. The absence of a specialist who oversaw CMV as a whole was identified as a flaw (box 2).

\section{Burden associated with caring for a child with congenital CMV}

Many participants suggested that the diagnosis of cCMV had a lasting impact on the family who were left overwhelmed with the life-changing experience. From the early stages of a cCMV diagnosis, there was a strong sense of uncertainty and unpredictability for families on what else may go wrong as a result of the 'fluctuating virus' and many participants viewed cCMV as a 'constant worry', 'dramatic uncertainty' and 'waiting game' in terms of how it may further affect their child.

Additionally, meeting everyday care needs, caring for a growing child who was fully dependant on them for an extended period of time, the constant monitoring and
Box 2 Quotes illustrating the difficulties associated with establishing a diagnosis of congenital cytomegalovirus (CMV)

- "The doctor snatched the dummy out of her mouth and said this is the problem. She says, it's made her glands swell and it's affected her hearing. She says, here is some ear drops and come back in a month, if it's not any better. So, I was a bit like never known that before, but she's a doctor and okay." (P3)

- "We were caught off guard by the diagnosis and it was handled so badly(....). She had a hearing loss identified in the new born screening and the audiology said, don't worry about it, it won't cause her any problems. They didn't tell us it could get worse and they didn't test for what had caused it. Having that really bad experience which meant she didn't have any antiviral treatment(....)We didn't know to watch out for her hearing deteriorating. I had sort of gut feeling that it was more than that. I wish I had acted on it. When you have specialists saying everything is fine. You take that. I don't think I got over that." (P5)

"There has been nobody that got kind of a CMV kind of overview. You immediately get sized and dotted for your child's deafness. Audiology deal with you. If your child has other issues, obviously physio we saw a little while. She gets occupational therapy, but they don't talk to each other. There is nobody, apart from the parent that has got that overview of what CMV can do. So that is a gap. I think all parents have found that there is no sort of, there is no CMV expertise, specifically." (P5)

the ongoing appointments were considered burdensome. Participants acknowledged the emotional aspects of caring and the worry for an unknown future. Furthermore, participants were concerned about the negative impact this may have on other siblings. Many participants expressed that having a child born with cCMV left them with a sense of grief and the grieving process being akin to 'the loss of a dream'. Many participants suggested that they felt frustrated, guilty and a sense of responsibility for not taking the necessary precautions to reduce the risk of CMV infection. Knowledge of risk reduction measures would have helped in ensuring that they were aware and remained cautious throughout their pregnancy. Participants emphasised the importance of 'arming women with information' for them to make their own informed decisions regarding the measures they choose to adopt, 'you educate them and then it's their choice' (box 3).

\section{Societal network: facilitators and barriers to coping}

Familial and community networks have the potential to contribute to the distress of carers or to support and alleviate their stress. For participants, the lack of knowledge and understanding of cCMV include that of the child's extended family who struggle to understand, empathise and effectively adjust to the child's disabilities. Participants believed that the lack of support from family and the wider community was in part due to the lack of awareness of cCMV and this also makes accessing support problematic. Many participants felt strongly about raising awareness of cCMV and educating the wider community. However, they were mindful to emphasise the importance 
Box 3 Quotes illustrating the burden associated with caring for a child with congenital cytomegalovirus (CMV)

- "Nobody really knows what the future holds for her. You are in this state of limbo, consistently with her, because it's obvious it had quite a big impact. There is no way of predicting anything, you are like, okay, brilliant. That is CMV(....)Devastating(...)And sort of increasing stages of devastation. As you learn more you get things confirmed. That is our experience of it(....)Lots of shocks I suppose. And gradual shocks ... it is not just a slap in the face things. It's sort of dawning realisations that are then confirmed or not and then you are left with I think dramatic uncertainty. That is almost probably the hardest bit of all of it and not knowing" (P7)

- "We will just have to keep monitoring it and keep monitoring her right ear, because it's a fluctuating virus. So obviously if it then got worse or they have to look into it again(...)It puts extra stress on me. I have appointments every week. I think because I constantly worry about it like its kind of my job to do the appointments and stuff because he works(....)l am constantly looking for it as well like looking for her hearing to drop or checking her eyesight ... It does, it puts that extra worry on you." (P2)

- "It's sort of still is a bit of a grieving process as well for the child you thought you were going to get vs the child you have." (P3)

- "When she was still so little it was quite hard to accept. You don't want that to be true. You want that- when a child is labelled with developmental delay, it kind of gives you a little bit of hope that there is some catching up that can be done. It's a slightly unusual term, because certainly for $E$ there was never any suggestion that she would ever properly catch up. Getting to that conclusion is kind of a process that you have to go through." (P8)

- "Obviously the guilt as a mother because shouldn't have contracted it but there you go(...)I just felt very guilty, ... You feel like okay, so if I hadn't of shared a spoon with my son and if I hadn't kissed him on the lips or made sure I washed my hands more thoroughly when I changed nappies or something maybe this wouldn't have happened. I think I probably did go through a phase of a bit of selfblame, I suppose. If anyone was going to be blamed for it, it was going to be me. No one else you could look to." (P6)

- "I think again its knowing the consequences of what could happen if you don't really. That's got to be the key(....)I wish l'd known it existed and it was a possibility that something could happen. Particularly being that I think, because I do have a toddler, I think I would, if I'd known how, with these messages I think I could have ramped up the hygiene a bit more." (P1)

of 'getting the message out without scaring people'. Similarly, others reaffirmed the need to give women the opportunity to make informed decisions to encourage risk reduction of contracting CMV (box 4).

\section{DISCUSSION}

The lived experience of parenting a child with cCMV covers a multitude of inter-related facets, including difficulties associated with CMV diagnosis, lack of awareness of CMV among medical professionals complicating the diagnosis process, the uncertainties about what the diagnosis might mean and, for some families, the ongoing experience of day-to-day life with a child with additional needs. Parents expressed their frustration of not knowing
Box 4 Quotes illustrating the theme of Societal networks: facilitators and barriers to coping

- "I think you know, even my closest family like my mum and my husband's parents, they don't get it really(....)They don't make any adjustments for her even though we have asked them to and told them that they need to. They sort of forget, I think I am trying to explain it more and they don't really take it in. We have sort of given up on that, because it's exhausting saying the same things over and over again(...)My mum would say, why is she doing that? What is she doing that for? I would say, well, you know, because of everything that's affecting her. Or she will say things like, you need to tell her off more. Why don't you discipline her and I am like well, some of her behaviour is the reason for it. She has got a big sensory issue going on. She is not an attention seeker." (P5)

- "I don't think there is so many birth problems that people have heard of. If no one has heard of CMV and you talk about it and everyone thinks, it's so rare. It's a niche." (P6)

- "So, all of that stuff is very stressful and just as stress, on stress, on stress. So, little is understood and known about CMV, it kind of makes it harder to make your case. If it's an obvious-if it's an Autism or something, you would go, yes, okay they are going to need more help. I think that has been a real issue is just the lack of professional support and advice as well as-I feel constantly under pressure to be on top of it and on the ball, because if I miss something or don't do something no-one else would pick it up. You can't rely on people around you." (P5)

- "Because they have seen $L$ and so they know, and I did get a pack of leaflets. I have given them to the schools and doctors and the nursery to try and get people." (P2)

CMV, cytomegalovirus.

about CMV during their pregnancies and consequently not having had the chance to take action to avoid infection. Family and wider societal networks have the potential to facilitate coping and alleviate stress. However, the lack of knowledge and awareness of CMV within social networks acts as a barrier to receiving support from family and friends. The lack of open dialogue and awareness of CMV among medical professionals, pregnant women, their families and wider society was considered the biggest barrier to reducing risk of CMV and also in coping with parenting a child with cCMV.

Consistent with previous research, our findings draw attention to the lack of awareness about congenital neurodevelopmental disabilities in childhood in medical circles and lack of a coordinated approach to diagnosis and post-diagnostic support, which leads to parents experiencing great emotional stress. ${ }^{30}$ The organisation of the healthcare system and the absence of teams with specialist CMV-specific knowledge, appear to increase burdens placed on parents, who faced uncertainty and delays in receiving a diagnosis for their child. Specific to parenting a child with cCMV, the participants in our study drew attention to the additional emotional burden of guilt and responsibility of potentially and unknowingly transmitting CMV to their unborn children which led parents, particularly mothers, to blame themselves on discovering that their child has cCMV. The need to identify a cause of 
the child's disability is related to closure and is part of the adaptive process. ${ }^{19}$ Families living with a child with cCMV were also resentful that they were not given an opportunity to participate in risk-reducing interventions in order to avoid contracting CMV.

Our findings on the emotions related to grief and loss are consistent with previous findings. ${ }^{31}$ The feelings of loss were for the ideal child they might have anticipated during pregnancy, as well as the loss of the child they might have experienced without the difficulties associated with cCMV. Parenting a child with cCMV, the uncertain diagnoses and prognoses, variable daily functioning, an apparent normal development of the child during the first few weeks and months, the manifestation of some symptoms but not others they had been warned about, and coping with an uncertain future contribute to feelings of ambiguous loss. ${ }^{32}$ Our findings suggest that social support from informal networks was perceived as supportive and vital to the daily care of their child with disabilities. However, lack of awareness, misjudgement of child's needs, stigma and discrimination hindered family functioning and coping. ${ }^{33}$

Although the study was limited to 10 participants, it provided rich data to highlight the experiences of parents living with a child with cCMV. The aim of qualitative research is not to reach generalisable findings, but to enable a richer understanding of the participants' experiences of the phenomena under investigation. The lack of the male/paternal perspective is an area that warrants further investigation.

We found that lack of knowledge about CMV is a significant problem and raising awareness of the condition among the general public, pregnant women and healthcare professionals, and providing education about riskreducing measures in pregnancy, is of vital importance. This will require a range of strategies including more emphasis placed on CMV in the undergraduate medical, nursing and midwifery curricula, focused postgraduate training for healthcare professionals and an organised programme of antenatal education for pregnant women and their families which should include written information in the handheld notes as well as inclusion of CMV in the list of infections discussed by midwives at booking. The effectiveness of this discussion is likely to be facilitated by increasing staff confidence as a result of more training. In addition, clear guidelines for the diagnosis and management of CMV in pregnancy, the newborn and child should be available in all NHS Trusts based on published national and international guidance in order to standardise the care given to these families. Wherever possible, a paediatric infectious diseases specialist should be involved in the management and coordination of care of these infants and children. ${ }^{44}{ }^{35}$ It should be recognised that the needs of families of affected children are complex and not limited to medical and practical considerations and, where possible, time should be given to families to explore the emotional and psychological dimensions of their child's condition. This may involve signposting families to support organisations, referring for formal psychological support and providing access to a consistent and familiar point of contact, for example a nurse specialist. There is need to conduct further research exploring the perceptions of healthcare professionals about their pre-existing knowledge about CMV, and collaborative work between healthcare professionals, affected families and advocacy organisations looking at how families' needs can most effectively be met.

Twitter Tushna Vandrevala @psych_tush

Acknowledgements The authors are grateful to the participants for their involvement and interest.

Contributors TV, VB and CEJ designed the study. VB collected the data and TV, VB AND EM-C analysed the data. TV prepared the manuscript with input from all authors. All authors approved the final draft.

Funding This paper presents independent research funded by the National Institute for Health Research (NIHR) under its Research for Patient Benefit (RfPB) Programme (Grant Reference Number PB-PG-0215-36120).

Disclaimer The views expressed are those of the author(s) and not necessarily those of the NIHR or the Department of Health and Social Care.

Competing interests None declared.

Patient and public involvement Patients and/or the public were involved in the design, or conduct, or reporting, or dissemination plans of this research. Refer to the Methods section for further details.

Patient consent for publication Not required.

Ethics approval Health Research Authority (HRA) South Central-0xford C Research Ethics Committee (16/SC/0683).

Provenance and peer review Not commissioned; externally peer reviewed.

Data availability statement Data are available upon reasonable request.

Open access This is an open access article distributed in accordance with the Creative Commons Attribution Non Commercial (CC BY-NC 4.0) license, which permits others to distribute, remix, adapt, build upon this work non-commercially, and license their derivative works on different terms, provided the original work is properly cited, appropriate credit is given, any changes made indicated, and the use is non-commercial. See: http://creativecommons.org/licenses/by-nc/4.0/.

ORCID iD

Tushna Vandrevala http://orcid.org/0000-0002-1140-8445

\section{REFERENCES}

1 Goderis J, De Leenheer E, Smets K, et al. Hearing loss and congenital CMV infection: a systematic review. Pediatrics 2014;134:972-82.

2 Townsend CL, Forsgren M, Ahlfors K, et al. Long-Term outcomes of congenital cytomegalovirus infection in Sweden and the United Kingdom. Clin Infect Dis 2013;56:1232-9.

3 Townsend CL, Peckham CS, Tookey PA. Surveillance of congenital cytomegalovirus in the UK and ireland. Arch Dis Child Fetal Neonatal Ed 2011;96:A46.

4 Luck SE, Wieringa JW, Blázquez-Gamero D, et al. Congenital cytomegalovirus: a European expert consensus statement on diagnosis and management. Pediatr Infect Dis J 2017;36:1205-13.

5 Turner KM, Lee HC, Boppana SB, et al. Incidence and impact of $\mathrm{CMV}$ infection in very low birth weight infants. Pediatrics 2014;133:e609-15.

6 Dollard SC, Grosse SD, Ross DS. New estimates of the prevalence of neurological and sensory sequelae and mortality associated with congenital cytomegalovirus infection. Rev Med Virol 2007;17:355-63.

7 Schleiss MR. Congenital cytomegalovirus: impact on child health. Contemp Pediatr 2018;35:7.

8 Cannon MJ, Westbrook K, Levis D, et al. Awareness of and behaviors related to child-to-mother transmission of cytomegalovirus. Prev Med 2012;54:351-7.

9 Reichman NE, Corman H, Noonan K. Impact of child disability on the family. Matern Child Health J 2008;12:679-83. 
10 Dlf.org.uk. Key facts | disabled living Foundation. Available: https:// www.dlf.org.uk/content/key-facts [Accessed 16 Aug 2019].

11 Hall HR, Graff JC. Parenting challenges in families of children with autism: a pilot study. Issues Compr Pediatr Nurs 2010;33:187-204.

12 Sanders JL, Morgan SB. Family stress and adjustment as perceived by parents of children with autism or Down syndrome: implications for intervention. Child Fam Behav Ther 1997:19:15-32.

13 Bayat M. Evidence of resilience in families of children with autism. $J$ Intellect Disabil Res 2007;51:702-14.

14 Vermaes IPR, Gerris JRM, Janssens JMAM. Parents' social adjustment in families of children with spina bifida: a theory-driven review. J Pediatr Psychol 2007;32:1214-26.

15 King G, Baxter D, Rosenbaum P, et al. Belief systems of families of children with autism spectrum disorders or Down syndrome. Focus Autism Other Dev Disab/ 2009;24:50-64.

16 Dumas JE, Wolf LC, Fisman SN, et al. Parenting stress, child behavior problems, and dysphoria in parents of children with autism, Down syndrome, behavior disorders, and normal development. Exceptionality 1991;2:97-110.

17 Eddy LL, Engel JM. The impact of child disability type on the family. Rehabil Nurs 2008;33:98-103.

18 Yamada A, Kato M, Suzuki M, et al. Quality of life of parents raising children with pervasive developmental disorders. BMC Psychiatry 2012;12:119.

19 Summers JA, Behr SK, Turnbull AP. Positive adaptation and coping strengths of families who have children with disabilities. In: Singer GHS, Irvin LK, eds. Support for caregiving families: enabling positive adaptation to disability. Baltimore: Paul $\mathrm{H}$. Brookes, 1988: $27-40$

20 Britner PAet al. Stress and coping: a comparison of self-reporting measures of functioning in families of young children with cerebral palsy or no medical diagnosis. J Child Fam Stud 2003;12:335-48.

21 Manning MM, Wainwright L, Bennett J. The double ABCX model of adaptation in racially diverse families with a school-age child with autism. J Autism Dev Disord 2011;41:320-31.

22 Mullins JB. Authentic voices from parents of exceptional children. Fam Relat 1987:36:30-3.
23 Vacca J, Feinberg E. Rules of engagement: initiating and sustaining a relationship with families. Infants Young Child 2000;13:51-7.

24 Revello MG, Tibaldi C, Masuelli G, et al. Prevention of primary cytomegalovirus infection in pregnancy. EBioMedicine 2015;2:1205-10.

25 Vandrevala T, Victoria B, Calvert A, et al. Understanding pregnant women's readiness to engage in risk reducing measures to prevent infections in pregnancy. Journal of Health Psychology 2019;5:1359105319884609.

26 Coyle A. Introduction to Qualitative psychological research. In: Lyons E, Coyle A, eds. Analysing qualitative data in psychology. London: Sage Publications, 2016: 9-30.

27 Braun V, Clarke V. Using thematic analysis in psychology. Qual Res Psychol 2006;3:77-101.

28 Elliott R, Fischer CT, Rennie DL. Evolving guidelines for publication of qualitative research studies in psychology and related fields. $\mathrm{Br} \mathrm{J}$ Clin Psychol 1999;38:215-29.

29 Yardley L. Dilemmas in qualitative health research. Psychol Health 2000;15:215-28.

30 Graungaard AH, Skov L. Why do we need a diagnosis? A qualitative study of parents' experiences, coping and needs, when the newborn child is severely disabled. Child Care Health Dev 2007;33:296-307.

31 Fernańdez-Alcántara M, García-Caro MP, Pérez-Marfil MN, et al. Feelings of loss and grief in parents of children diagnosed with autism spectrum disorder (ASD). Res Dev Disabil 2016;55:312-21.

32 O'Brien M. Ambiguous loss in families of children with autism spectrum Disorders*. Fam Relat 2007;56:135-46.

33 Cuzzocrea F, Murdaca AM, Costa S, et al. Parental stress, coping strategies and social support in families of children with a disability. Child Care Pract 2016;22:3-19.

34 Shah T, Luck S, Sharland M, et al. Fifteen-minute consultation: diagnosis and management of congenital CMV. Arch Dis Child Educ Pract Ed 2016;101:232-5

35 Rawlinson WD, Boppana SB, Fowler KB, et al. Congenital cytomegalovirus infection in pregnancy and the neonate: consensus recommendations for prevention, diagnosis, and therapy. Lancet Infect Dis 2017:17:e177-88. 